\title{
Educar pela Pesquisa - uma abordagem para o desenvolvimento e utilização de Softwares Educacionais
}

\author{
Ana Carolina Bertoletti \\ Márcia Cristina Moraes \\ Roque Moraes \\ Antônio Carlos da Rocha Costa
}

Resumo: Este artigo que como objetivo apresentar o educar pela pesquisa como uma abordagem para o desenvolvimento e utilização de softwares educacionais. $\mathrm{O}$ Educar pela Pesquisa visa inovar a prática em sala de aula. Tal inovação se caracteriza pela motivação e incentivo dos alunos, por parte dos professores, pelo gosto e necessidade da pesquisa em aula. Para tanto deve ocorrer uma mudança no papel do professor e aluno, ambos devem contribuir significativamente na reconstrução do conhecimento. A reconstrução do conhecimento é considerada o critério diferencial da pesquisa, englobando teoria e prática, filosofia base do Educar pela Pesquisa. Através do SAEP-NET mostraremos como inserir o Educar pela Pesquisa de Pedro Demo em um sistema de apoio a professores, considerando o ciclo dialético proposto por Moraes, Galiazzi e Ramos, que representa a pesquisa em sala de aula como um ciclo composto por "questionamento", "construção de argumentos" e "comunicação".

Palavras-chaves: ambientes virtuais de aprendizagem, educar pela pesquisa e software educacional.

Education through Research - an approach for the development and use of education software

Abstract: This paper intends to present the Education through Research as an approach for the development and use of education software. The Education through research aims to innovate the practice in classroom motivating students to do research as an everyday activity. This implies some changes in the roles of teachers and students because both have to contribute for knowledge reconstruction. Knowledge reconstruction is considered the differential criteria, joining theory and practice, the

* Artigo elaborado a partir do projeto interinstitucional SAEP-NET - Sistema de Apoio ao Educar pela Pesquisa na Internet, financiado pela FAPERGS através do edital PROADI 3/2001.

** Professora, doutoranda em Informática na Educação (PGIE/UFRGS), professora e pesquisadora da UPF, carolina@upf.br. http://vitoria.upf.br/ carolina

Professora, doutoranda em Ciência da Computação (II/UFRGS), professora da PUCRS, mmoraes@inf.ufrgs.br.

Professor, Doutor em Educação, professor e pesquisador da PUCRS, searom@pucrs.br.

****** Professor, Doutor em Ciência da Computação, professor e pesquidor da UCPel, rocha@atlas.ucpel.tche.br. 
main philosophy of education through research. In this paper we are going to present a way to incorporate these ideas on a system called SAEP-NET.

Keywords: learning virtual environment, education through research and education software

\section{Introdução}

A crescente evolução e utilização de novas tecnologias têm provocado uma transformação na sociedade, que está cada vez mais se tornando uma sociedade baseada na informação e no conhecimento. $\mathrm{O}$ advento da informática no meio escolar é um reflexo desta transformação. Atualmente, a potencialidade do computador como instrumento didático para o ensino é muito valorizada e pode ser observada através da: grande quantidade de softwares didáticos produzidos e disponíveis no mercado, da procura, cada vez maior por softwares educacionais e, principalmente, o crescente número de usuários conectados à Internet com a finalidade de buscar informações.

Segundo Almeida (1998), esta transformação implica em novas idéias de conhecimento e de aprendizagem, da função da escola e do papel do professor e do aluno. Neste sentido, Demo (1997) salienta que a pesquisa assume um papel fundamental nessa nova etapa da educação.

Demo em (Demo 1997), demonstra que o interesse está voltado a fundamentar a importância da pesquisa para a educação, querendo chegar até o ponto de tornar a pesquisa uma maneira própria de aprender. Nessa nova maneira de aprender, o aluno passa de objeto do ensino para parceiro de trabalho, assumindo-se sujeito do processo de aprender.

Neste sentido, Demo (1997) apresenta uma nova abordagem educacional, o educar pela pesquisa, que tem como base o questionamento reconstrutivo. No questionamento reconstrutivo, a construção do conhecimento se dá através de uma reformulação de teorias e conhecimentos existentes. O questionamento reconstrutivo encaminha um novo tipo de construtivismo, em que, retira-se a ênfase da construção e direciona-a para uma reconstrução do conhecimento.

A reconstrução do conhecimento é considerada o critério diferencial da pesquisa, englobando teoria e prática, filosofia base do Educar pela Pesquisa. Dessa maneira, o Educar pela Pesquisa requer que o professor e o aluno manejem a pesquisa como princípio científico e educativo e a tenham como atitude cotidiana (Demo 1997). Moraes et al. (2002) visualizam o Educar pela Pesquisa como um ciclo dialético composto de três momentos: questionamento, construção de argumentos e comunicação e avaliação.

A Internet, como um grande repositório de informações, é um meio apropriado para o desenvolvimento de sistemas que suportem esta nova abordagem da educação. Neste sentido, o SAEP-NET (Sistema de Apoio ao Educar pela Pesquisa na Internet) visa apoiar a prática do Educar pela Pesquisa, considerando um ciclo dialético proposto por Moraes et al. (2002).

A construção do SAEP-NET disponibiliza uma ferramenta que se baseia em uma abordagem educacional tanto para o seu desenvolvimento quanto em sua utilização. Desta maneira, o educar pela pesquisa é aplicado como uma concepção para o desenvolvimento de softwares educacionais e traz contribuições tanto para a educação quanto para o desenvolvimento de sistemas e para a pesquisa. 
Do ponto de vista educacional, o sistema visa difundir a abordagem conhecida como Educar pela Pesquisa, que enfatiza a importância da pesquisa no processo de aprendizado. Assim como Demo e Moraes acreditamos que a pesquisa deve ser considerada como elemento chave no processo de aprendizagem que ocorre no dia a dia das escolas e universidades, pois a pesquisa busca instigar o aprendiz, incentivando-o a participar do processo de reconstrução do conhecimento que efetivamente leva a aprendizagem.

Do ponto de vista do desenvolvimento de programas e sistemas computacionais voltados à aprendizagem, o sistema contribui para a inovação de uma linha educacional ainda pouco explorada no ambiente de sala de aula e em softwares educacionais. Acreditamos que o educar pela pesquisa ainda não é amplamente aplicado na sala de aula devido ao pouco, ou nenhum, conhecimento dos educadores em relação a esta abordagem. Uma das maneiras mais eficientes e rápidas de difundir conhecimento atualmente é através da Internet. Neste sentido, o desenvolvimento de um sistema computacional como o SAEP-NET possibilita a difusão do educar pela pesquisa e conseqüentemente amplia a sua utilização na sala de aula.

Do ponto de vista da pesquisa, o sistema enfoca a questão da adaptação das tecnologias disponíveis na Internet para apoiar a prática do Educar pela Pesquisa. A Internet é um ambiente bastante favorável a pesquisa e conseqüentemente a prática do educar pela pesquisa, pois possui ferramentas que possibilitam a busca de informações e a comunicação entre as pessoas, duas características essenciais para o Educar pela Pesquisa como iremos observar ao longo do artigo.

Neste artigo iremos apresentar uma maneira de abordar as questões propostas pelo educar pela pesquisa em um sistema computacional chamado SAEP-NET. Desta maneira, o artigo irá descrever uma breve fundamentação teórica do educar pela pesquisa, uma visão de softwares educacionais e o enquadramento do SAEP-NET nesta visão, e a arquitetura geral do sistema mostrando como os pressupostos do educar pela pesquisa podem ser mapeados para um sistema computacional.

\section{Estado atual do conhecimento no assunto}

O desenvolvimento de softwares educacionais é baseado em duas concepções educativas bastante distintas. A primeira delas é o paradigma comportamentalista onde ocorre à ênfase na transmissão de conhecimento do sujeito que sabe para o sujeito que deseja aprender. A segunda é o paradigma construtivista caracterizado por uma compreensão do aprender como construção, com envolvimento ativo e reflexivo do aluno.

Dentre as variantes do segundo paradigma se enquadra o educar pela pesquisa, desenvolvido inicialmente por Pedro Demo (1997). O educar pela pesquisa propõe uma modificação na forma do educar, considerando importante a participação do aluno no processo de aprendizagem, incentivando-o através da realização de projetos e trabalhos de pesquisa desenvolvidos em sala de aula.

\subsection{Educar pela Pesquisa}

Educar pela pesquisa tem como objetivo incentivar o questionamento dentro de um processo de reconstrução de conhecimento. Este processo pode ser entendido como a produção de um conhecimento inovador que inclui interpretação própria, formulação pessoal, saber pensar e aprender a aprender. Desta maneira, educar pela pesquisa é ir contra a cópia, a condição de objeto e a manipulação do aluno (Moraes 2002). 
Segundo Demo (1997) o educar pela pesquisa se dá na forma de programa construtivo acompanhado. Desta maneira, a pesquisa pode ser entendida por um conjunto de tarefas que ao serem executadas levam a reconstrução de alguma teoria ou conteúdo. Demo considera o questionamento reconstrutivo a base para o educar pela pesquisa e isto implica em uma transformação do entendimento da palavra aprender, que passa do aprender com o significado de memorizar para o aprender com significado de reconstruir.

Como esta abordagem pretende superar o ensinar, o instruir, o treinar e o domesticar, incentiva e forma a autonomia crítica no sujeito (Demo 1997). Isto acarreta uma mudança tanto no papel do aluno quanto do professor. O aluno deixa de ser um simples receptor de informações para tornar-se um aprendiz ativo no processo de reconstrução do seu conhecimento. O professor deixa de ser o detentor único do conhecimento e passa a ser o orientador e parceiro dos alunos durante o processo (Williams 1995).

O questionamento reconstrutivo é um termo bastante amplo e engloba diferentes fases para a reconstrução crítica do conhecimento. Moraes et al. (2002) visualizam o processo do educar pela pesquisa como um ciclo dialético composto por três fases: questionamento, construção de argumentos e comunicação. A primeira fase inicia-se através do questionamento de teorias e conteúdos existentes. Nesta fase são apontadas falhas e limitações nos objetos de estudo e procura-se identificar novos caminhos para ampliar os seus entendimentos. Contudo, estes novos caminhos devem possuir uma base teórica sólida. Assim encaminha-se a segunda fase, onde ocorre a construção de argumentos para solidificar as novas idéias. Após os argumentos terem sido construídos e organizados eles devem ser comunicados. Isto constitui a terceira fase, que tem como objetivo colocar os argumentos produzidos para a análise e avaliação de um grupo maior. A partir desta análise podem surgir novas criticas o que pode desencadear um novo movimento no ciclo, ou seja, um novo questionamento, uma nova construção de argumentos e uma nova comunicação. Assim o educar pela pesquisa pode ser visto como um movimento interativo e recursivo.

Considerando o esquema apresentado em Moraes (2002) (Figura 1), que representa a pesquisa em sala de aula como um ciclo dialético composto por "questionamento", "construção de argumentos" e "comunicação", argumentamos que cada uma destas fases pode ser desenvolvida dentro de um sistema que permita a utilização do educar pela pesquisa tanto como uma metodologia para o desenvolvimento de softwares educacionais quanto o próprio sistema para apoiar o aprendizado.

Dentro da abordagem do educar pela pesquisa, o processo de entrar em contato com a informação pode ser considerado um elemento central. Neste sentido as redes de computadores, em especial a Internet, podem trazer contribuições importantes, devido à facilidade de acesso a informações dispersas nas mais diferentes fontes. Como sugerido por Demo (1997), a informatização do conhecimento irá absorver a transmissão do conhecimento, pois é mais atraente, manejável e atinge um maior número de pessoas. Contudo, entendemos que a Internet além de substituir a transmissão de conhecimento traz outros tipos de contribuições para pesquisa em sala de aula, pois através dela os estudantes e professores podem facilmente explorar várias fontes de conhecimento, levantar questões, procurar respostas, solucionar problemas propostos (Williams 1995), e interagir uns com os outros. 


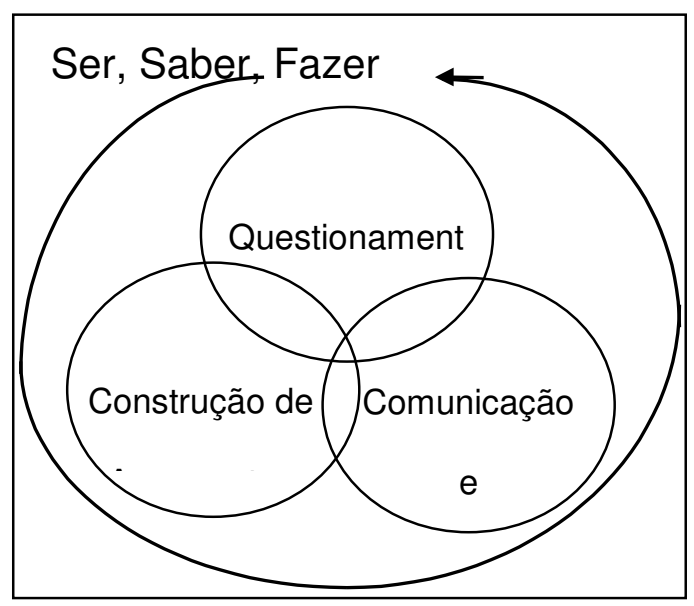

Figura 1: Ciclo dialético da pesquisa em sala de aula

A Internet possibilita aos estudantes e professores acesso a um rico repositório de informações que podem estar na forma de textos, gráficos, figuras, sons, imagens e vídeo. Além disso, permite realizar visitas "virtuais" a museus localizados em diferentes partes do mundo e participar de grupos de discussão nacionais e internacionais.

Neste trabalho estudamos os diferentes serviços oferecidos pela Internet a fim de identificá-los como partes integrantes de cada uma das fases que constituem o educar pela pesquisa. Acreditamos que, através da busca e recuperação de informações, o estudante terá em suas mãos um referencial teórico bastante forte para o questionamento e construção de seus argumentos. Já os serviços para a troca de idéias e informações num grupo de pessoas e entre grupos, podem ser bastante úteis para a comunicação e crítica dos argumentos construídos.

\subsection{Softwares Educacionais}

Um software educacional pode ser visto como todo o programa utilizado com uma finalidade educacional. Encontramos na literatura diferentes formas de se classificar o software educacional. Gamez (1998) apresenta a seguinte taxonomia de classificação:

- Exercício e Prática: tipo de programa que tem como objetivo exercitar conteúdos ou habilidades já conhecidas pelo aluno, mas não inteiramente dominadas por ele. O aluno possui a sua disposição um conjunto de exercícios e pode realizálos quantas vezes forem necessárias.

- Tutorial: tipo de programa responsável pela apresentação de conteúdos, utilizando animações, sons e gerenciamento do controle da performance do aprendiz, facilitando o processo de administração das lições e possíveis programas de recuperação. 
- Sistema Tutor Inteligente: tipo de programa que tem como objetivo considerar o conhecimento e habilidades prévias dos aprendizes para escolher estratégias de ensino aprendizagem mais apropriadas para cada um dos aprendizes.

- Simulação e Modelagem: tipo de programa que tem como objetivo representar ou modelar parte do mundo real como objetos, sistemas ou eventos. Estes modelos exploram a simulação de situações de risco, como manipulação de substâncias químicas e controladores de vôo e experimentos complicados ou caros.

- Jogo Educativo: tipo de programa que proporciona uma fonte de recreação com vistas à aquisição de um determinado tipo de aprendizagem. As tarefas de negociação, persuasão e cooperação existente nos jogos buscam incentivar e atrair o aprendiz para o processo de aprendizagem.

- Informativo: tipo de programa que visa apresentar informações na forma de textos, gráficos ou tabelas. Se enquadram nesta categoria livros eletrônicos, enciclopédias interativas e programas que buscam apresentar informações específicas.

- Hipertexto/Hipermídia: tipo de programa comumente definido como uma forma não linear de armazenamento e recuperação de informações. Desta forma, um hipertexto tem como principal característica à capacidade de interligar pedaços de informação entre si através do uso de palavras-chaves.

Com base na taxonomia descrita em Gamez (1998) podemos constatar que o SAEPNET se enquadra na categoria de hipertexto/hipermídia, visto que é um sistema desenvolvido para Internet e herda suas características naturais.

A hipermídia é vista como a forma mais eficiente para refletir a metodologia do Educar pela Pesquisa em um software educacional, considerando o ciclo dialético. A capacidade de interligar diferentes pedaços de informações e a facilidade de comunicação entre pessoas distantes geograficamente faz da hipermídia uma excelente ferramenta para disponibilizar recursos que promovam as três fases do ciclo dialético: "questionamento", "construção de argumentos" e "comunicação". Neste sentido, a hipermídia é de fundamental importância para a implementação da abordagem do Educar pela Pesquisa em um software educacional.

\section{Descrição do SAEP-Net}

O Sistema de Apoio ao Educar pela Pesquisa na Internet é um software educacional que visa proporcionar um ambiente na Web para auxiliar professores e alunos na prática do Educar pela Pesquisa.

Neste sentido, o SAEP-NET é composto pelos três momentos envolvidos no Educar pela Pesquisa: questionamento, construção de argumentos e comunicação e avaliação. Cada um desses momentos é visto como um módulo.

Além destes módulos o sistema disponibiliza material de consulta sobre o Educar pela Pesquisa. Auxiliando os professores a se familiarizar com esta nova metodologia e, ao mesmo tempo, ter acesso aos textos produzidos pelo grupo de educação do projeto.

Os usuários do sistema terão a sua disposição, futuramente, um guia virtual para ajudá-los durante a navegação. Este guia conhecerá as informações contidas no sistema e poderá indicar para o usuário o significado das possíveis ações. Estes guias serão baseados na estrutura definida por Moraes (1999). 
A figura 2 representa um esquema geral do sistema, apresentando a organização dos módulos e suas opções de trabalho. A elipse do Educar pela Pesquisa representa a filosofia da abordagem adotada no sistema, mais especificamente ela está relacionada a documentação que estará disponível aos usuários.

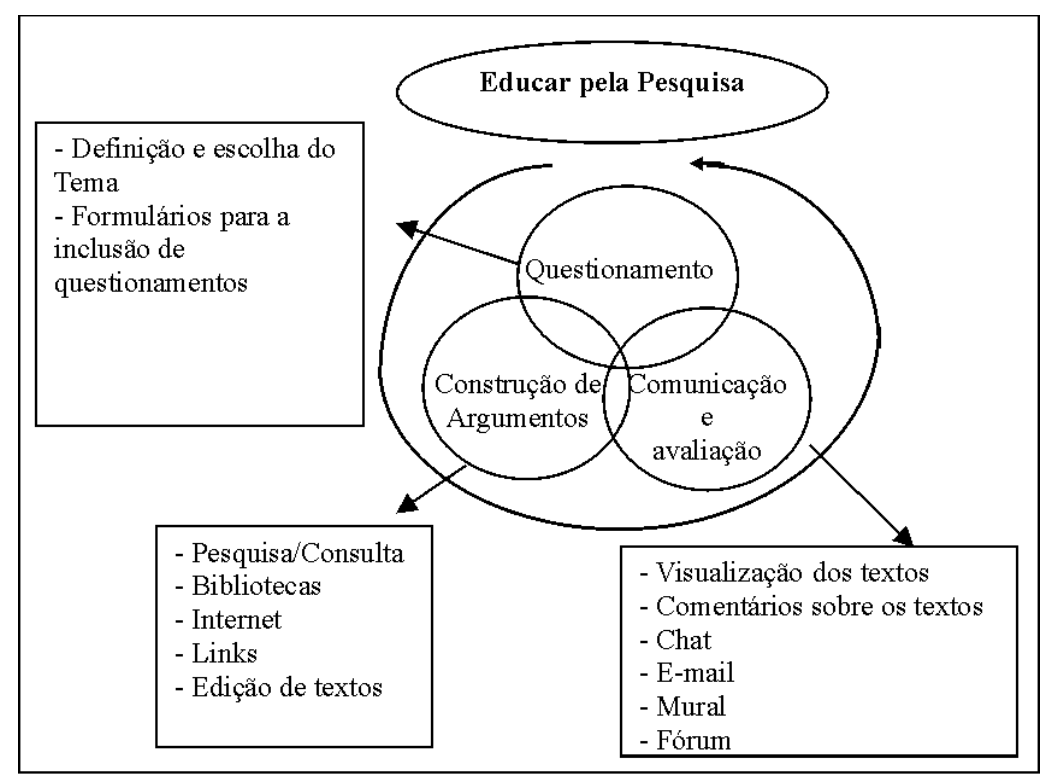

Figura 2: Esquema geral do sistema

\subsection{Módulo de questionamento}

No módulo de questionamento o usuário define o tema a ser discutido durante $\mathrm{o}$ processo. A definição do tema pode ser realizada por diferentes tipos de usuários, tanto professores quanto alunos podem iniciar o processo através do questionamento. Definido o tema se inicia a fase de inclusão dos questionamentos através de formulários. Tanto os temas quanto os questionamentos podem ser visualizados por qualquer usuário do sistema.

\subsection{Módulo de construção de argumentos}

No módulo de construção de argumentos o usuário tem a sua disposição os serviços necessários para busca de informações, que serão utilizadas como embasamento teórico para o questionamento estudado. Neste módulo o usuário pode ter acesso a bibliotecas virtuais, links para sites de busca e liberdade para navegar pela Internet. Uma das tarefas que fazem parte do momento de construção de argumentos é a produção de um texto. No educar pela pesquisa os alunos devem produzir um texto que contenha reflexões e análise crítica do assunto que está sendo pesquisado. A produção escrita é um aspecto bastante importante dentro do educar pela pesquisa. Neste sentido, o sistema proposto possui uma ferramenta para upload de documentos.

Essa ferramenta faz parte do módulo de construção de argumentos. A inclusão desta ferramenta neste módulo é interessante, pois, na medida em que o usuário obtém informações, as interpreta e as assimila ele pode desenvolver o seu próprio texto. Este texto inicialmente é privado ao usuário e somente o mesmo poderá lê-lo e alterá-lo. Quando o usuário achar conveniente ele pode tornar o texto público e os demais 
usuários do sistema poderão ter acesso a ele. Tornar um texto público significa expô-lo a crítica e avaliação de um grupo maior. Esta é uma das maneiras de desencadear o processo de comunicação e análise dos argumentos produzidos para um questionamento, é uma das maneiras de se iniciar o terceiro momento envolvido no educar pela pesquisa.

\subsection{Módulo de comunicação}

No módulo de comunicação e avaliação o usuário tem acesso as ferramentas responsáveis pela troca de informações e integração entre os participantes do processo. Uma das formas de integração é a avaliação dos textos produzidos realizadas em cooperação entre os usuários (que podem ser professores e alunos). Para realizar esta avaliação, os usuários têm acesso aos textos de seus colegas e podem apresentar comentários. Estes comentários são exibidos junto com o texto, ficando disponíveis tanto para o autor quanto para os demais leitores.

Outra forma de comunicação é a realização de reuniões virtuais periódicas realizadas através de uma ferramenta síncrona, o chat. Para a discussão dos assuntos relacionados as reuniões e demais comentários, podem ser utilizadas as ferramentas de e-mail, mural (ilustrada na figura 3) e fórum, as quais permitem uma comunicação assíncrona. Com o mural e o fórum os usuários têm a possibilidade de visualizar todas as mensagens enviadas, enquanto no e-mail os usuários podem escolher um destinatário único ou um grupo. Para viabilizar o envio de mensagens para grupos, podem ser utilizadas as listas de discussão.

\subsection{Fase atual de desenvolvimento}

É importante salientar que o SAEP-NET ainda se encontra em fase de desenvolvimento. Adicionalmente, todo o ambiente que envolve alunos, ferramentas de comunicação e, principalmente, materiais instrucionais para pesquisa, deve possuir, fundamentalmente, uma manutenção periódica. No momento, estamos definindo o módulo de manutenção do sistema. Este módulo está disponível apenas para o professor e é responsável, entre outros, pelo cadastro de alunos e controle de login.

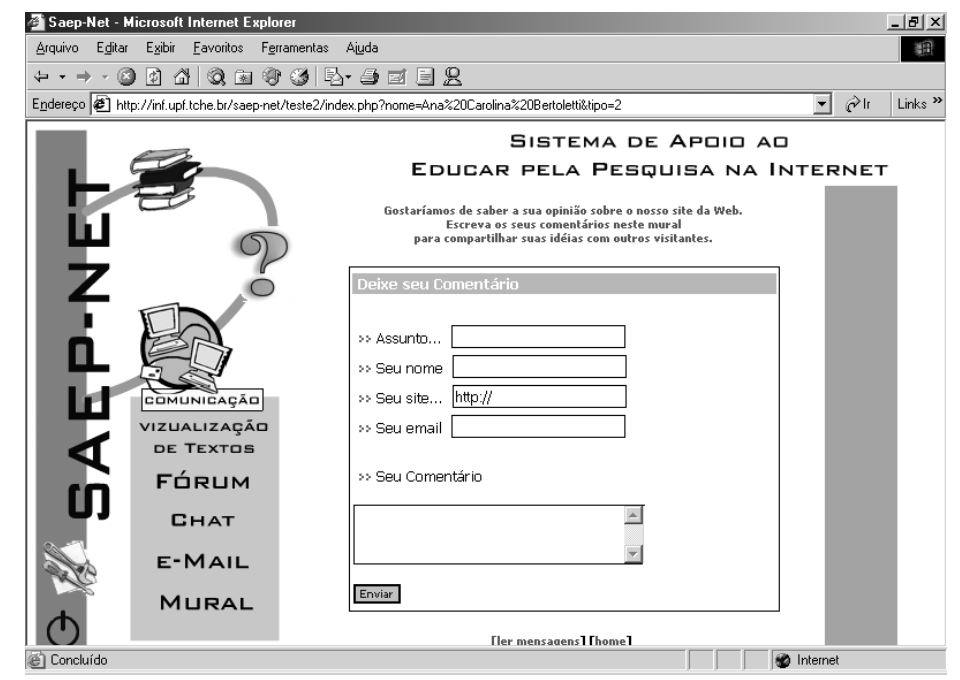

Figura 3 - Mural de comunicação do SAEP-NET 


\section{Conclusões}

Este artigo teve como propósito básico apresentar o educar pela pesquisa como uma abordagem para o desenvolvimento e utilização de software educacional. Adicionalmente, foi mostrado, através do SAEP-NET, como inserir essa nova abordagem em um sistema de apoio a professores que visam inovar a prática em sala de aula. Tal inovação se caracteriza pela motivação e incentivo dos alunos, por parte dos professores, pelo gosto e necessidade da pesquisa em aula.

Este trabalho, eminentemente multidisciplinar, é inovador tanto no que se refere a não existência de softwares que utilizem o educar pela pesquisa como metodologia para o seu desenvolvimento, quanto no que se refere a não existência de softwares que promovam o educar pela pesquisa, que promovam a autoria de atividades, considerando a prática do educar pela pesquisa.

Neste sentido, apresentamos uma forma de concepção de softwares educacionais inovadora do ponto de vista educacional, do ponto de vista de desenvolvimento de programas e sistemas computacionais voltados à aprendizagem, e do ponto de vista da pesquisa.

É importante salientar que este trabalho está sendo realizado em parceria com um grupo de educação que já aplica o educar pela pesquisa em sala de aula e que tem adaptado algumas das tecnologias existentes para a prática do educar pela pesquisa. Contudo, o grupo argumenta que esta adaptação não consegue refletir corretamente a metodologia de trabalho e que seria interessante trabalhar com um sistema projetado para a prática do educar pela pesquisa.

Desta maneira, assim que concluirmos a implementação do SAEP-NET, iremos realizar uma avaliação do software com o grupo de educação a fim de identificar pontos positivos e negativos do sistema que devem ser revisados e aperfeiçoados.

\section{Agradecimentos}

Agradecemos a Fundação de Amparo a Pesquisa do Rio Grande do Sul (FAPERGS) pela oportunidade de realizar esse projeto interinstitucional apoiado pelo edital PROADI 03/2001.

\section{Referências Bibliográficas}

ALMEIDA, Maria Elizabeth B. Informática na Escola: da atuação à formação de professores. Net. Artigos selecionados sobre Informática e Educação. 1998. Disponível por: http://www.divertire.com.br/

DEMO, Pedro. Educar pela Pesquisa. Campinas, SP: Autores Associados, 1997.

DEMO, Pedro. Questões para a Teleducação. Petrópolis, RJ: Editora Vozes, 1998.

GAMEZ, L. Ticese: Técnica de Inspeção de Conformidades Ergonômicas em Software Educacional. Dissertação de Mestrado. Universidade de Minho. Guimarães, Portugal.

MORAES, Márcia Cristina, BERTOLETTI, A. C. \& COSTA, A. C. R. Evaluating Usability of SAGRES Virtual Museum Considering Ergonomics Aspects and Virtual Guides. In: 7th World Conference on Computers in Education - WCCE. Copenhagen, 2001. 
MORAES, Márcia Cristina. Uma arquitetura de agentes improvisacionais para apoio a visitação de museus baseada em computadores. Dissertação de Mestrado. Porto Alegre: Mestrado em Informática/PUCRS, 1999.

MORAES, Márcia Cristina. Do Ponto de Interrogação ao Ponto: A Utilização dos Recursos da Internet para o Educar pela Pesquisa. In: MORAES, R.; RAMOS, M. \& GALIAZZI, M.C. (Eds.) Pesquisa em Sala de Aula: Fundamentos e pressupostos. Porto Alegre: PUCRS, 2002.

MORAES, Roque. Produção numa sala de aula com pesquisa: superando limites e construindo possibilidades. In: Revista da Educação - Educação e Ciências e Questões Afins. Porto Alegre, RS: EDIPUCRS, 2000.

MORAES, Roque; RAMOS, Maurivan \& GALIAZZI, Maria do Carmo. Pesquisa em Sala de Aula: Fundamentos e pressupostos. 2002.

MORAN, José Manuel. Mudar a forma de ensinar e de aprender com tecnologias. Net. Artigos selecionados sobre Informática e Educação. 1998. Disponível por: http://www.divertire.com.br/

RYDER, Kandall; James \& HUGHES, Tom. Internet for Educators. Upper Saddle River, New Jersey: Prentice-Hall Inc, 1997.

SCHAVER, Helmut; MUEHLBACHER; Joerg; LENG, Paul; SHAVE, Michael; AIKEN, Robert. Interactive Seminar using the Web: An International Experience. In: Teleteaching'98 Distance Learning, Training and Education. Pp. 869-875.

WILLIAMS, Bard. The Internet for Teachers. Foster City, CA: IDG Books Worldwide, Inc, 1995. 